\title{
The Effects of Motor Skill Interventions on Motor Skills in Children with Developmental Disabilities: A Literature Review
}

\author{
Byungmo Ku${ }^{1 *}$ \\ ${ }^{1}$ Vanguard University of Southern California, USA
}

Received: May 28, 2020
Accepted: August 25, 2020
Published online: October 31, 2020
Keywords:
Developmental Disability
Intervention
Motor Development
Motor Skills
Check for
updates

\section{ABSTRACT}

OBJECTIVES Children with developmental disabilities experience motor skill deficits from childhood. Participation in motor skill intervention may be a promising way to promote their motor skills. The purpose of this study was to review the effectiveness of motor skill interventions on motor skills in children with disabilities.

METHODS To select relevant articles about motor skill interventions for children with developmental disabilities, a search of a database with pre-determined search terms and a manual search were implemented. After screening 476 articles, 21 studies were included in the current study. The studies were systematically summarized, and theories of motor development were discussed.

RESULTS Participation in motor skill intervention may be a way to promote motor skills in children with developmental disabilities. Dynamic system theory, Newell's model and Stodden's model can be used as a framework for motor skill interventions.

CONCLUSIONS Ample evidence exist indicating motor skill interventions are effective to promote motor skills in children with developmental disabilities. The motor skill interventions should be provided to children with developmental disabilities.

(c) The Asian Society of Kinesiology and the Korean Academy of Kinesiology

\section{Introduction}

Developmental disabilities (DD) refer to combined conditions caused by an impairment in physical, learning, language, or behavior areas [1]. This includes but is not limited to attention-deficit/hyperactivity disorder, autism spectrum disorder, cerebral palsy, hearing loss, intellectual disability, vision impairment, and other developmental delays [1]. DD are a global health issue among all racial, ethnic, and socioeconomic groups. One in six, or about $14 \%$, of

*Correspondence: Byungmo Ku, Division of Natural, Physical and Health Sciences, Vanguard University of Southern California, Costa Mesa, CA, 92626, USA; E-mail: Byungmo.ku@vanguard.edu children aged 3 through 17 years had one or more DD [1]. Children with DD tend to need more time and repetitive practice to master daily tasks because of their difficulty with memory, motivation, and attention [2]. In addition to the core characteristics of DD, motor skill deficits are a common characteristic in children with DD [3].

Motor skills refers to a voluntary goal-oriented movement that is learned or relearned and requires the use of limbs and skills in which both the movement and the outcome of action are emphasized [3, 4]. Motor skills are generally categorized into two types: gross and fine motor skills. The development of children's gross motor skills is essential for optimal physical 
and social development, athletic performance and daily activities [5]. Fine motor skills play an important role in daily activity performance such as dressing and feeding [6]. Strong fine motor skills in children are related with higher academic achievement, such as mathematical and earlier reading development $[7,8]$. Even though a number of studies indicates the importance of motor skills in children, children with DD experience motor skill deficits from early childhood.

Individuals with autism spectrum disorder (ASD) experience motor skill deficits, which present at an early age $[9,10]$. Motor skill deficits are not currently used to phenotype individuals with ASD, yet one study suggests that persistent head-lag, a progressive aspect of motor development, is one of the earliest defining features of ASD [11]. In the study, infant siblings of children with ASD were measured prospectively by a pull-to-sit test from 6 to 36 months, and the presence of persistent head-lag at 6 months had strong associations with a confirmed ASD diagnosis at 36 months of age. Other common motor skill deficits indicated in early development include delayed postural development [12], delayed interceptive actions (catching, hitting, and kicking), and core balance ability [13]. In addition, children with ASD aged from 5 10 years showed significant gross motor skill delays when compared to their age matched peers [14].

Children with attention deficit hyperactivity disorder (ADHD) experience more deficits in both fine and gross motor skills than children without ADHD [15]. Moreover, Developmental Coordination Disorder (DCD) is often considered as a comorbidity of ADHD [16]. Children with ADHD display slower and more heterogeneous reaction times compared to children without disabilities [17given the association between ADHD and impairments in motor control, we hypothesized that slower or more variable reaction times might also correlate with motor development. The aim of this case-control study was to explore the relationship between motor function, reaction speed and variability, and ADHD. After comprehensive educational and clinical assessments, motor skill development was evaluated in 35 children ages 9 to 14 (19 with ADHD]. Moreover, ADHD children with high levels of inattention experience poorer motor skill performance than ADHD children with hyperactivity or impulsivity [18]. A large body of literature has found that children with intellectual disability experience motor skill deficits [19] - [22]. A study found that youth with ID had lower motor skills than youth without disabilities after controlling for age and gender. The authors of this study also indicated that children's weight status (high BMI) may partially affect their motor skills [19]. The severity of ID may be one of the factors negatively impacting the motor skills of children with ID [22]. A study found that objectively measured locomotor motor skills of children with mild ID are significantly lower than in children with borderline ID.

One of the main characteristics of cerebral palsy (CP) is limited development of movement and posture [23]. If a region of the brain (e.g., primary motor cortex) is impaired or damaged before, during, or after birth, it is likely to lead to postural control dysfunction with deficits in postural networks [24]. This is known as a factor related to gross motor skills such as upper and lower limb activities [25, 26]. Children with $\mathrm{CP}$ have lower product-oriented fundamental motor skill scores compared to children without cerebral palsy [27]. A systematic review including 17 studies indicated that people with $\mathrm{CP}$ experience running inefficiency, meaning that they expend more energy when running compared to people without CP [28]. As ample evidence indicates that children with DD experience motor skill deficits, it is important to promote their motor skills.

Participation in motor skill intervention is one of promising ways to promote motor skills in children with and without disabilities [29,30]. Motor skill intervention provides children with organized and structured opportunities to learn about motor skills. Children's motor skills are reinforced and practiced in the interventions by researchers, teachers, coaches, or parents. Types of motor skill intervention include but are not limited to physical activity-based, technologybased, family-involved, and group-based interventions. Logan and colleagues found a moderate effectiveness of motor skill intervention on motor skills in children without disabilities ( $\mathrm{d}$ $=0.39, p<0.001$ ). Specifically, the study indicated that object control and locomotor skills significantly improved from preto post-intervention $(\mathrm{d}=0.41, p<0.001 ; \mathrm{d}=0.45, p<0.001)$. Even though the effectiveness of motor skill intervention for 
children without disabilities has been well studied, the effects of motor skill intervention on motor skills in children with DD remain unclear.

The current study, therefore, reviewed the effects of motor skill intervention on motor skills in children with DD by focusing on five different types of disability: autism spectrum disorder, developmental coordination disorder, attention-deficit hyperactivity disorder, intellectual disability, and cerebral palsy. Moreover, widely used theories (e.g., dynamic system theory, Newell's model, and Stodden's model) explaining motor skill development were explained to support findings.

\section{Text}

The current study conducted a literature review search to examine the effectiveness of motor skill interventions for motor skills in children with DD. Inclusion criteria for the current systematic review were as follows: a) peer-reviewed article, b) printed in English, c) a publication date between January 1990 and June 2018, d) presence of motor-related term, disability-related term, and child-related term in the title and/or abstract, and e) intervention study (structured motor skill programs were provided to children with DD).

\section{Search strategy}

An electronic database: Psycinfo was used for the literature searches. The search terms used for the current study for the database included: "motor skill*” AND "intervention" AND "disabilit*" AND "child*". The initial search produced 476 articles. A primary author (BMK) and a research assistant reviewed the articles. After screening articles, the number of articles included in the current study was $n=21$.

\section{Data extraction}

Data from the included studies were extracted by a primary author based on the purpose of this study. The following data were extracted: author name, published date, country of study, study design, characteristics of participants (sample size, age, and sex) intervention approach, intervention length, setting, outcome measure, and targeted skills and main results. [Table 1] includes this information.
Note. $\mathrm{ASD}=$ Autism spectrum disorder, $\mathrm{CP}=$ cerebral palsy, DCD = developmental coordination disorder, ID = intellectual disability, DD = developmental disabilities (studies include different types of developmental disabilities), PDMS = Peabody developmental motor scales, TGMD = test of gross motor development, $\mathrm{MABC}=$ Movement assessment battery for children, GMFM = Gross motor function measure

\section{Results}

Based on the current review, ample evidence suggests that participation in motor skill intervention significantly and positively influences motor skills in children with DD. Most studies in the current review indicated that motor skills in experimental groups improved compared to baseline (pre vs. post). However, this result should be interpreted with caution because a randomized control trial which confirms causal effects of motor skill intervention has not been widely implemented. Of the 21 studies, only three studies were randomized control trials, two of which did not find outcome differences between experimental groups and control groups $[31,32]$. This may indicate that motor skill improvements through non-randomized control trial studies in children with DD may have occurred by chance. Higher quality studies such as a randomized control trial should be done to scrutinize the effectiveness of motor skill intervention. In the current review, the sample size of studies ranged from three to 233. Most of the studies had a relatively small sample size, except for two studies [32,33]. With small number of participants, most studies have generalizability issues. Although participant recruitment is a common issue in disability-related studies, it is recommended to have appropriate sample size with reporting power analysis.

In the current review, as children aged, the targeted motor skills tended to shift from fundamental motor skills to sportrelated skills. For example, for younger children with DD (1 7 years old), common targeted skills were object control skills (e.g., throwing, catching, and hitting) or locomotor skills (e.g., walking, running, and jumping) [34-36]. For older children with DD (above 8 years old), however, sports-related skills such as swimming, bicycling, ball shooting, and dribbling skills were widely studied [37-39]. These represent age- 


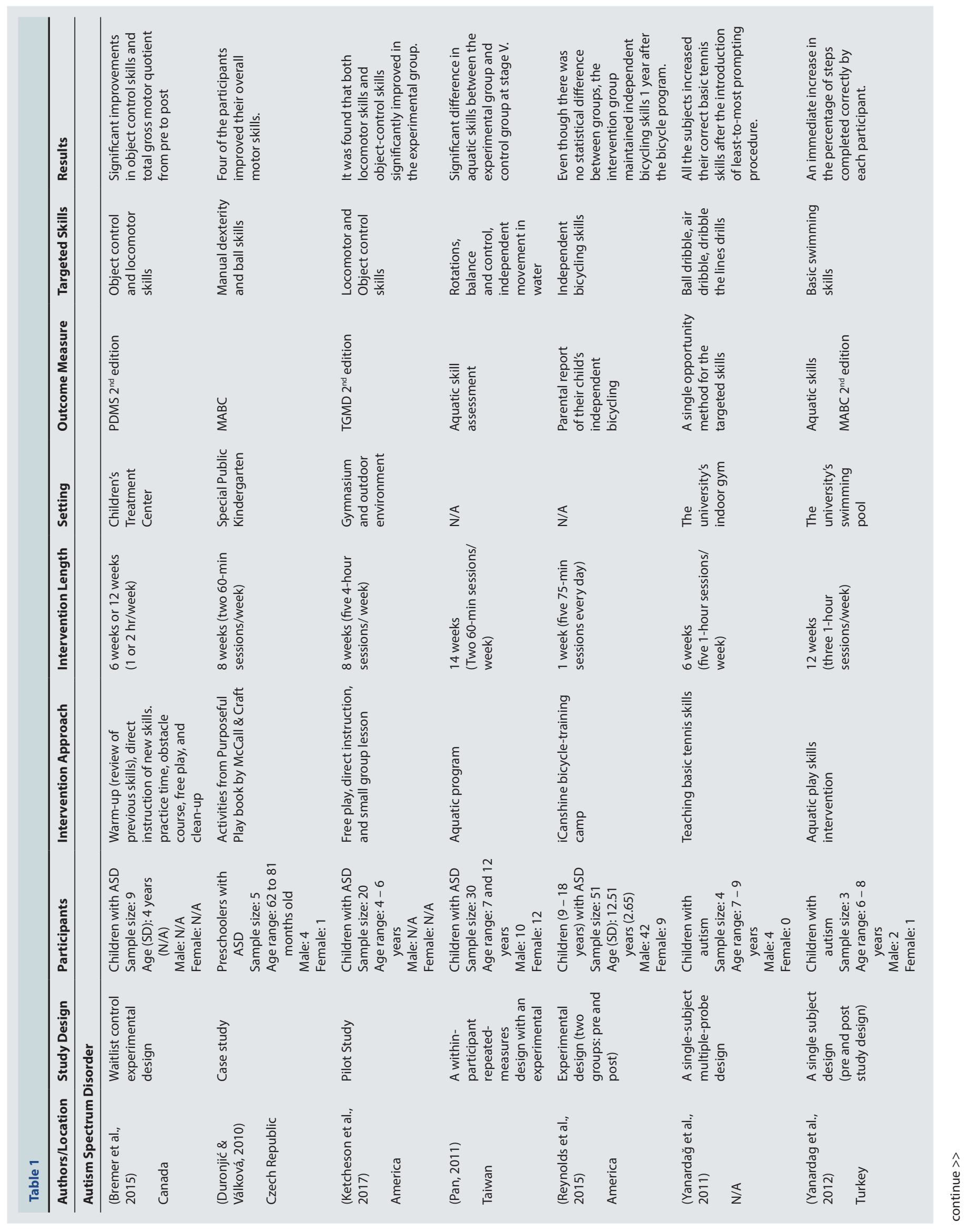




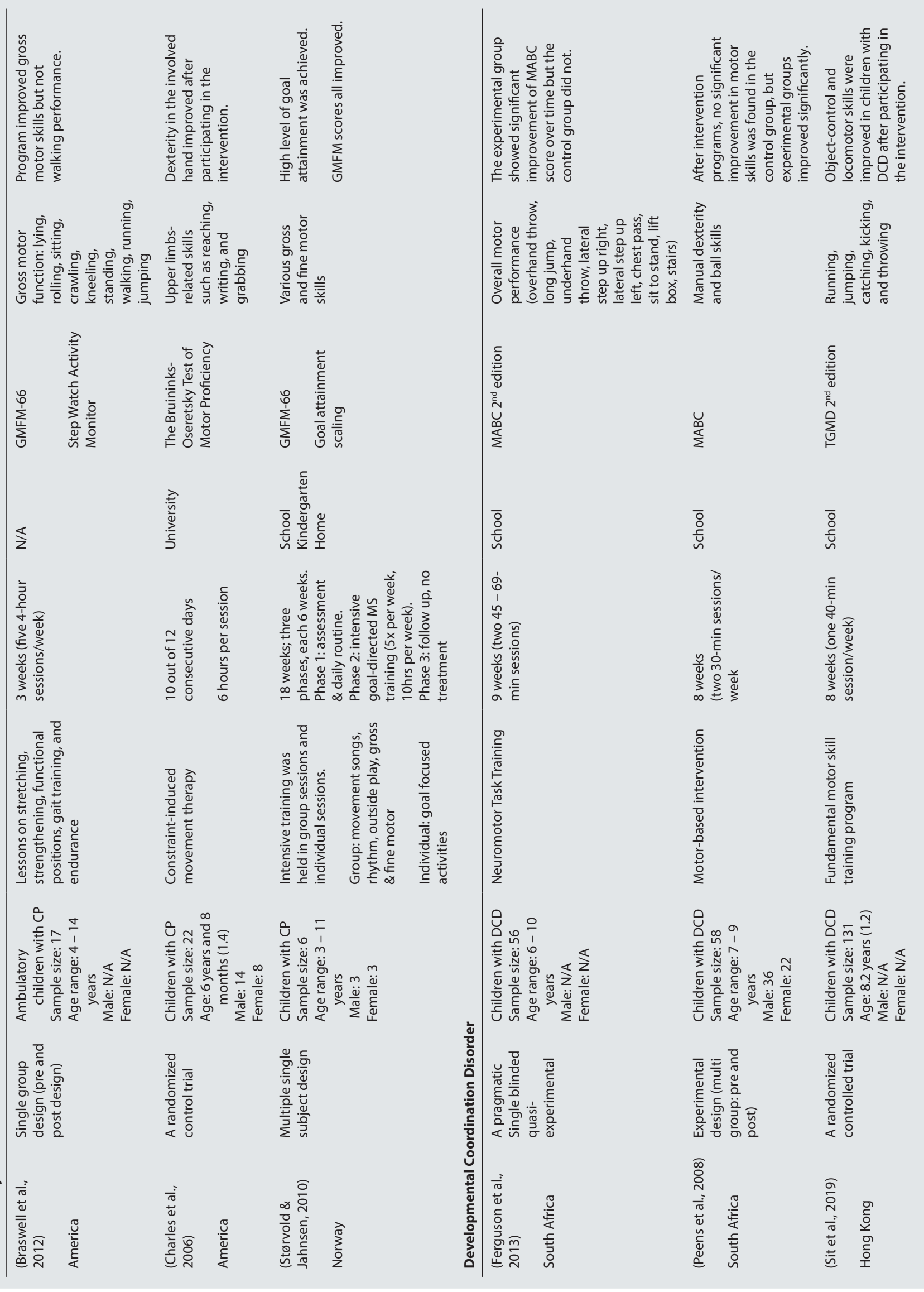




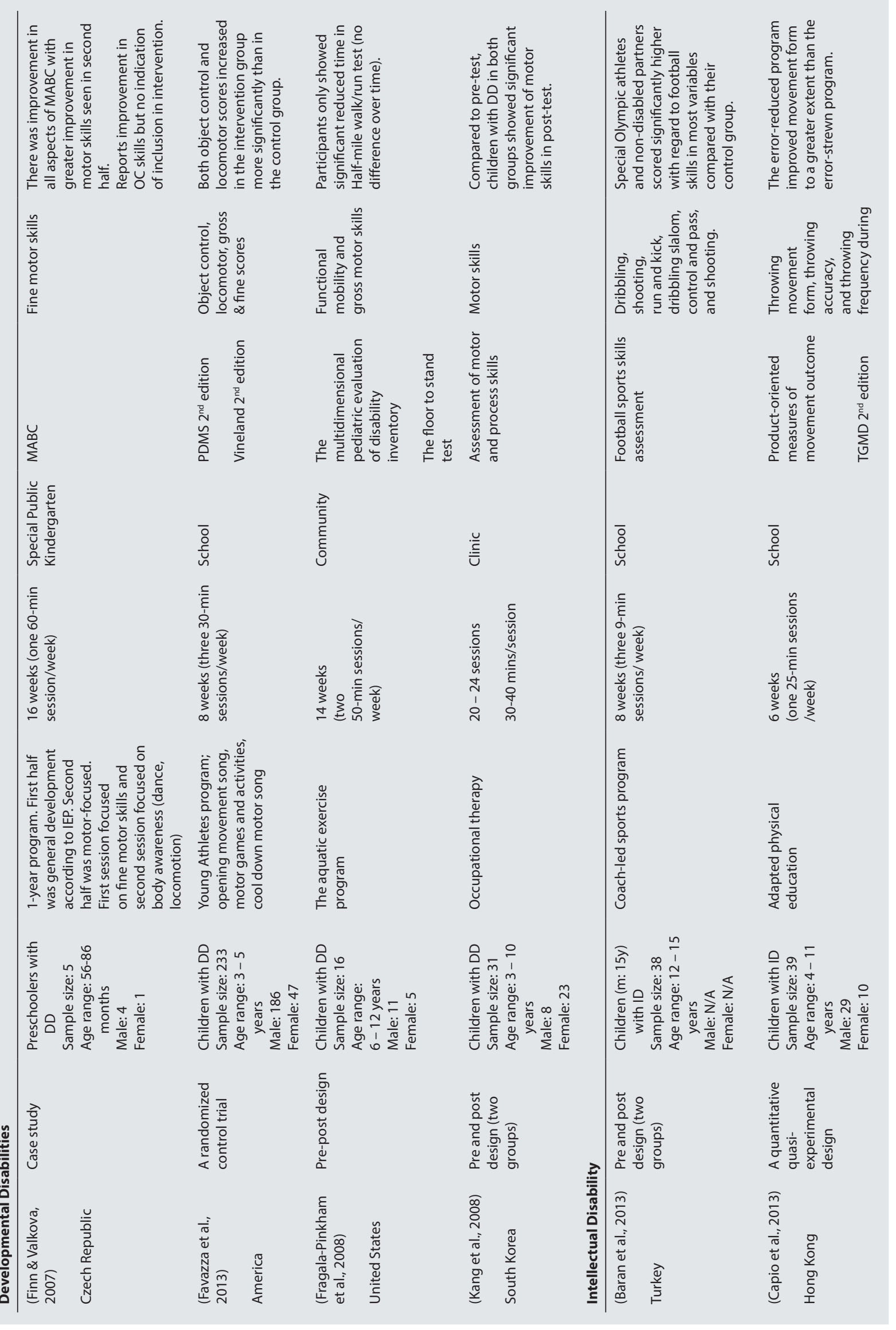



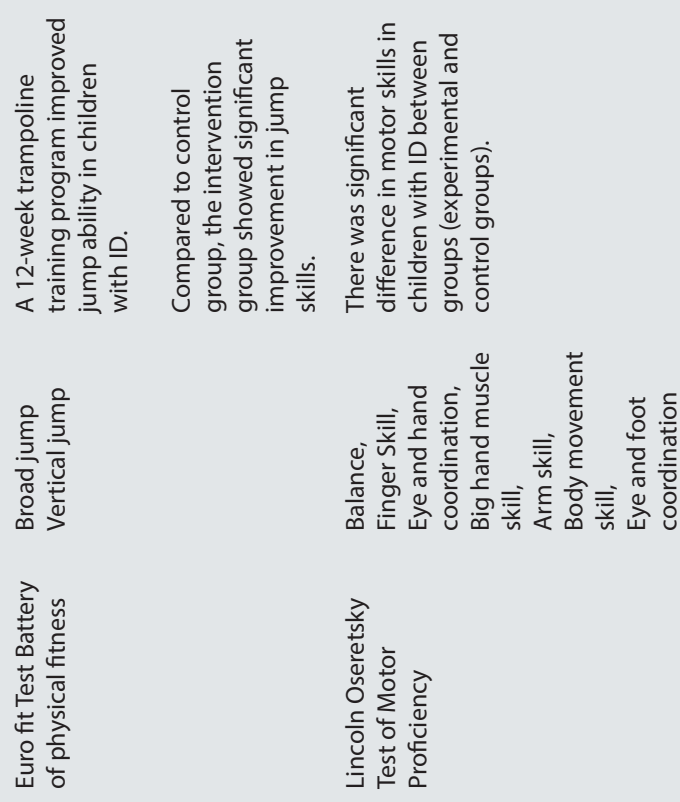

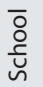

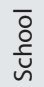
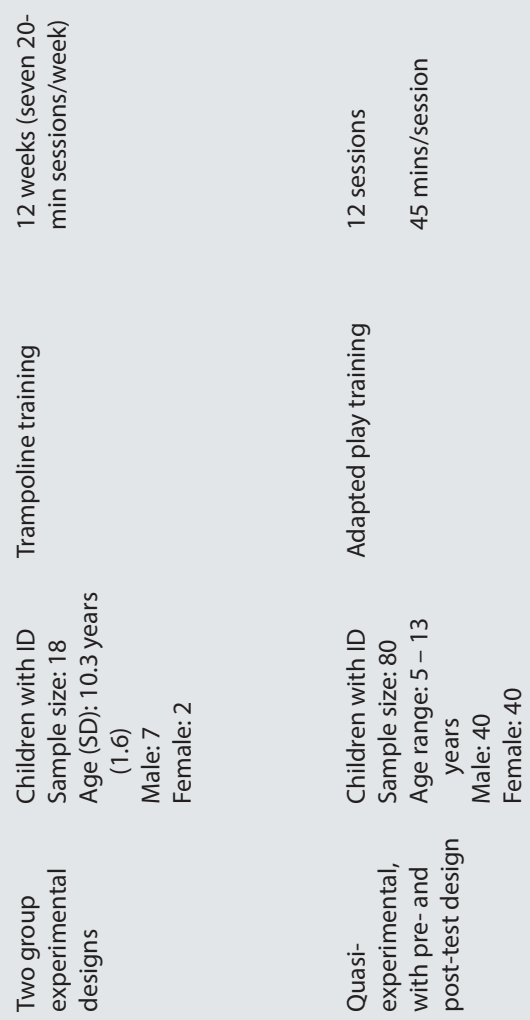

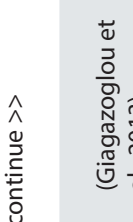

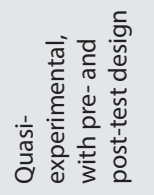

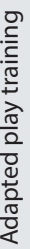

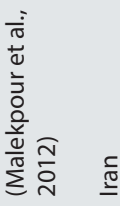

related motor development in children [40]. According to the mountain of motor development (40), children aged from one to seven years develop fundamental motor skills, and after that period, children begin to learn context-specific motor skills. Even though age does not guarantee improvement of motor skills, it is important for interventionists to provide chronological age-related interventions because chronological age is still a driving force for motor skill development. Moreover, age-matched intervention is important for children with DD from a social participation perspective. Specifically, participating in an intervention may be a starting point allowing them to socialize with their peers. For example, school-aged children can socialize with their peers by playing sports such as basketball and soccer. If children with DD do not participate in aged-matched intervention, it may be challenging for them to continue to participate in the intervention, which in turn leads to limited opportunities to socialize with their peers.

Based on the results of the current review, intervention length (i.e., frequency and duration) may be a factor that influences the effectiveness of motor skill intervention. Most studies in the current review provided motor skill interventions to children with DD for more than 16 hours and found motor skill improvement in children with DD. This is aligned with a meta-analysis including 18 studies, which found that the intervention length was a moderator for the association between participation in motor skill intervention and motor skills in children with ASD [29]. Studies that provided 16 total hours or more had significantly larger effects on motor skills in children with ASD compared to studies that provided less than 16 hours [29]. From a human motor development perspective, this may apply in other populations, such as children with developmental coordination disorder or ADHD.

In the current review, intervention types varied from physical activity-based programs to occupational therapy, depending on study purposes. One of the common characteristics of successful interventions was that intervention contents were matched to targeted motor skills. For example, if a researcher targeted object control skills in children with $\mathrm{DD}$, the intervention contents were highly related with object 
control skills. Sit's study (2019) is an impressive example of this [32]. The study was a randomized controlled trial and found significant effects of the motor skill intervention. They targeted running, jumping, catching, kicking, and throwing skills in children with DCD and offered a fundamental motor skill training program which focused on the five motor skills. If targeted skills and intervention programs are not matched, the effectiveness of the intervention may be reduced. A study targeted gross motor skills and functional mobility in children with DD, but they provided an aquatic aerobic exercise program which was not highly related with the targeted motor skills [41]. This study only found a negligible effect of the intervention on functional mobility and gross motor skills in children with DD. Thus, the intervention contents should be directly related with targeted motor skills to improve the effectiveness of motor skill intervention in children with disabilities.

Even though more research should be done to examine the mechanism for the relationship between participation in motor skill interventions and improved motor skills in children with disabilities, possible explanations for the relationship may be found in theories of motor development. These theories include but are not limited to the dynamic system theory [42], Newell's model [43], and Stodden's model [44].

\section{Theories of motor development}

The dynamic system theory is one of the most well-known approaches to explaining motor development. It conceptualizes the combination of complicated nonlinear systems in physics and mathematics with traditional biological and psychological approaches. There are two main concepts of dynamic system theory: (1) development should be understood in the context of multiple, mutual, and continuous interaction between all levels of the developing system and (2) development should be understood in the nested processes that disentangle over many timescales [42]. Even though these concepts can be applied to all different species, the dynamic system theory specifically targets the process of human development. Traditional developmentalists considered newly learned behavior as originating from either the organism or the environment. However, a more recently accepted explanation is that development is affected by both the organism and the environment. In the theory, this pattern is explained by selforganization, which refers to the body's ability to identify a stable pattern within the context of the body's characteristics [45]. For example, one characteristic of people with $\mathrm{CP}$ is their crouch gait. Within the dynamic system theory, the crouch gait is the walking pattern that is maximized within the physical and neurological characteristics of ambulatory children with $\mathrm{CP}$, even though they spend more energy when walking compared to children without $\mathrm{CP}$. These are often considered attractor states, which means that the body modifies their ability in a preferable way depending on constraints (i.e., factors that influence motor behavior) [42]. In other words, the body's ability in individuals with $\mathrm{CP}$ uses crouch gait as an attractor state to maximize their ability to walk by interacting with constraints.

Newell (1986) categorized the constraints into three different types: individual, task, and environmental < Figure $>$ [43]. The individual constraint subdivides into structural (i.e., physical characteristics of humans, such as height and weight) and functional (i.e., psychological states of humans, such as attention and motivation) constraints. Motor behaviors are influenced by these two components. For example, there are two persons who play basketball. One person is highly motivated but the other person is demotivated toward playing basketball. Even though they have the same basketball skills, the motivated person may show better performance (i.e., motor behavior) compared to the other during a game because of the functional constraint (i.e., motivation). Environmental constraints refer to factors that influence motor behavior from outside the individual, such as weather, surface of the ground, and peers. For instance, an individual's basketball dribbling skills may vary depending on where they dribble (e.g., sand vs. hard surface). Lastly, task constraints include the goals, rules, and equipment that influence motor behavior. During a basketball game, the reason why players do not kick the basketball is because of the kick ball rule. If there were no kick ball rule in the basketball game, players could use legs as well. This suggests that human motor behavior is affected by task constraints. It is important to note that as each constrain is related to the others, the effects of constraints on motor 
behavior is not straightforward but complex, suggesting that motor development is non-linear and should be interpreted by considering multiple factors $<$ Figure $1>$.

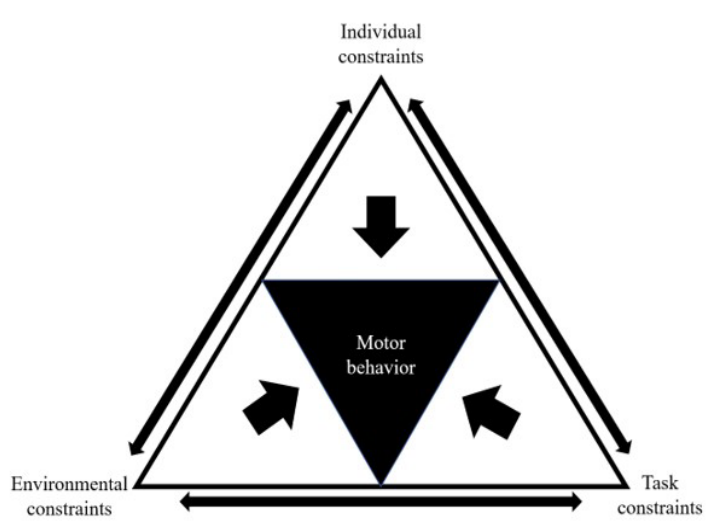

Figure 1. Newell's constraints model. Note: Figure adapted from Newell (1984).

Another model that has been widely used in explaining motor development is Stodden's model (2008) [44]. This model highlights the bi-directional relationship between physical activity and motor skill development. This means that even though motor skill proficiency is a factor that impacts participation in physical activity, conversely, physical activity has also been considered as a factor that influences the motor skill development of children [47]. A study confirmed that in pre-school-aged children, engaging in moderate to vigorous physical activity (MVPA; activities that take moderate or hard physical effort and make an individual breather somewhat hard or much harder than normal) was significantly associated with total movement skill scores $(r=0.18, p<0.001)$, but lightintensity physical activity (activities that take the least amount of physical effort and make an individual breather a little bit harder than normal) was not related with the motor skills of children [48]. Another study found that pre-school-aged children who had higher levels of MVPA were least likely to be in the low motor skill tertile compared to children who had lower levels of MVPA [49]. This association was clearer in four-year-old children than in three-year-olds. Due to the fact that fundamental motor skill development is an emerging stage in three-year-olds, motor skills may be less of a facilitator for PA participation compared to the motor skills of children aged four.
Other studies investigated this association, focusing on type of PA [50] and duration of PA (51). In a study, physical activity (very active indoor and outdoor play) was significantly correlated with a specific type of motor skill development (throwing at a target, running speed; $r=0.24$, $p=0.01 ; \mathrm{r}=0.21, p=0.03$ ) [50]. The authors indicated that one possible mechanism is that children can use their whole musculature and power-related ability, which are connected to improving running velocity and jumping distance during outdoor play. Moreover, the duration of PA was associated with motor difficulty in pre-school aged children [51]. In this study, children who participated in PA less than 840 mins/wk were significantly more likely to experience motor difficulty (MABC- $2 ;<5^{\text {th }}$ percentile) than children who participated in physical activity over $840 \mathrm{~min} / \mathrm{wk}(\mathrm{OR}=2.3$; 95\% CI:10, 5.1).

A recent study suggests that physical activity behaviors in young children with DD were associated with their motor skills $(\beta=0.20, p<0.001)$ [52]. In this study, $6 \%$ of the motor skills of young children with DD were explained by the children's physical activity behaviors and parental factors. The authors of this study suggest that even though physical activity participation influences motor skill development in young children with developmental disabilities, it does not guarantee the improvement of motor skills. Therefore, to maximize a child's motor skills, the motor skills should be taught, reinforced, and practiced [55]- [56]. To promote motor skills in children with DD, interventionist should embrace the theory-related frameworks into their interventions and encourage children with DD to participate in the interventions [56].

\section{Conflicts of Interest}

The author declares no conflict of interest.

\section{References}

1. Boyle CA, Boulet S, Schieve LA, Cohen RA, Blumberg SJ, Yeargin-Allsopp $M$, et al. Trends in the prevalence of developmental disabilities in US children, 1997-2008. Pediatrics. 2011; 127(6):1034-1042.

2. Odom L, Horner H, Snell E. Handbook of developmental 
disabilities. Guilford press; 2009.

3. Skinner RA, Piek JP. Psychosocial implications of poor motor coordination in children and adolescents. Hum Mov Sci. 2001; 20(1-2):73-94.

4. Cools W, Martelaer K De, Samaey C, Andries C. Movement skill assessment of typically developing preschool children: a review of seven movement skill assessment tools. J Sports Sci Med. 2009; 8(2):154-168.

5. Dumith SC, Gigante DP, Domingues MR, Kohl HW. Physical activity change during adolescence: A systematic review and a pooled analysis. Int J Epidemiol. 2011; 40(3):685-698.

6. Marr D, Cermak S, Cohn ES, Henderson A. Fine motor activities in head start and kindergarten classrooms. Am J Occup Therapy. 2003; 57(5):550-557.

7. Cameron CE, Brock LL, Murrah WM, Bell LH, Worzalla SL, Grissmer D, et al. Fine motor skills and executive function both contribute to kindergarten achievement. Child Dev. 2012; 83(4):1229-1244.

8. Luo Z, Jose PE, Huntsinger CS, Pigott TD. Fine motor skills and mathematics achievement in East Asian American and European American kindergartners and first graders. Brit J Dev Psychol. 2007; 25(4):595-614.

9. Lloyd M, MacDonald M, Lord C. Motor skills of toddlers with autism spectrum disorders. Autism. 2013; 17(2):133-146.

10. Provost B, Lopez BR, Heimerl S. A comparison of motor delays in young children: Autism spectrum disorder, developmental delay, and developmental concerns. J Autism Dev Disord. 2007; 37(2):321-328.

11. Flanagan JE, Landa R, Bhat A, Bauman M. Head lag in infants at risk for autism: A preliminary study. Am J Occup Ther. 2012; 66(5):577-585.

12. Nickel LR, Thatcher AR, Keller F, Wozniak RH, Iverson JM. Posture development in infants at heightened versus low risk for autism spectrum disorders. Infancy. 2013; 18(5):639-661.

13. Whyatt CP, Craig CM. Motor skills in children aged 7-10 years, diagnosed with autism spectrum disorder. J Autism Dev Disord. 2012; 42(9):1799-1809.

14. Liu T, Hamilton M, Davis L, ElGarhy S. Gross motor performance by children with autism spectrum disorder and typically developing children on TGMD-2. J Child Adolesc Behav. 2014; 2:123

15. Willcutt EG. The Prevalence of DSM-IV Attention-deficit/ hyperactivity disorder: A meta-analytic review. Vol. 9, Neurotherapeutics. 2012. p 490-499.

16. Barkley RA. Attention-deficit hyperactivity disorder: A handbook for diagnosis and treatment. Guilford Publications; 2014. p 898

17. Klotz JM, Johnson MD, Wu SW, Isaacs KM, Gilbert DL. Relationship between reaction time variability and motor skill development in ADHD. Child Neuropsychol. 2012; 18:576-585.

18. Papadopoulos N, Rinehart N, Bradshaw JL, McGinley JL. Brief report: Children with ADHD without Co-morbid autism do not have impaired motor proficiency on the movement assessment battery for children. J Autism Dev Disord. 2013; 43(6):1477-1482.

19. Frey GC, Chow B. Relationship between BMI, physical fitness and motor skills in youth with mild intellectual disabilities. Int J Obes. 2006; 30(5):861-867.

20. Hartman E, Houwen S, Scherder E, Visscher C. On the relationship between motor performance and executive functioning in children with intellectual disabilities: Motor and executive functioning in children with ID. J Intellect Disabil Res. 2010; 54(5):468-477.

21. Simons J, Daly D, Theodorou F, Caron C, Simons J, Andoniadou E. Validity and reliability of the TGMD2 in 7-10-year-old Flemish children with intellectual disability. APAQ. 2008; 25(1):71-82.

22. Westendorp M, Houwen S, Hartman E, Visscher C. Are gross motor skills and sports participation related in children with intellectual disabilities? Res Dev Disabil. 2011; 32(3):1147-1153.

23. Blair E, Love S. Definition and classification of cerebral palsy. Dev Med Child Neurol. 2005; 47(8):510-510.

24. Dewar R, Love S, Johnston LM. Exercise interventions improve postural control in children with cerebral palsy: a systematic review. Dev Med Child Neurol. 2015; 57(6):504-520.

25. van der Heide JC, Begeer C, Fock JM, Otten B, 
Stremmelaar E, van Eykern LA, et al. Postural control during reaching in preterm children with cerebral palsy. Dev Med Child Neurol. 2004; 46(4):253-266.

26. Woollacott MH, Shumway-Cook A. Postural dysfunction during standing and walking in children with cerebral palsy: What are the underlying problems and what new therapies might improve balance? Neural Plast. 2005; 12(2-3):211-219.

27. Capio CM, Sit CHP, Abernethy B, Masters RSW. Fundamental movement skills and physical activity among children with and without cerebral palsy. Res Dev Disabil. 2012; 33(4):1235-1241.

28. Chappell A, Gibson N, Morris S, Williams G, Allison GT. Running in people with cerebral palsy: A systematic review. Physiother Theory Pract. 2019; 35(1):15-30.

29. Case L, Yun J. The Effect of different intervention approaches on gross motor outcomes of children with autism spectrum disorder: A meta-Analysis. APAQ. 2019; 36(4):501-526.

30. Logan SW, Robinson LE, Wilson AE, Lucas WA. Getting the fundamentals of movement: a meta-analysis of the effectiveness of motor skill interventions in children: Effectiveness of motor skill interventions. Child Care Health Dev. 2012; 38(3):305-315.

31. Charles JR, Wolf SL, Schneider JA, Gordon AM. Efficacy of a child-friendly form of constraint-induced movement therapy in hemiplegic cerebral palsy: a randomized control trial. Dev Med Child Neurol. 2006; 48(08):635.

32. Sit CH, Yu JJ, Wong SH, Capio CM, Masters R. A schoolbased physical activity intervention for children with developmental coordination disorder: A randomized controlled trial. Res Dev Disabil. 2019; 89:1-9.

33. Favazza PC, Siperstein GN, Zeisel SA, Odom SL, Sideris $\mathrm{JH}$, Moskowitz AL. Young athletes program: Impact on motor development. APAQ. 2013; 30(3):235-53.

34. Bremer E, Balogh R, Lloyd M. Effectiveness of a fundamental motor skill intervention for 4-year-old children with autism spectrum disorder: A pilot study. Autism. 2015; 19(8):980-991.

35. Duronjić M, Válková $H$. The influence of early intervention movement programs on motor skills development in preschoolers with autism spectrum disorder (case studies). Acta Gymnica. 2010; 40(2):37-45.

36. Ketcheson L, Hauck J, Ulrich D. The effects of an early motor skill intervention on motor skills, levels of physical activity, and socialization in young children with autism spectrum disorder: A pilot study. Autism. 2016; 1362361316650611.

37. Baran F, Aktop A, Özer D, Nalbant S, Ağlamış E, Barak S, et al. The effects of a Special Olympics Unified Sports Soccer training program on anthropometry, physical fitness and skilled performance in Special Olympics soccer athletes and non-disabled partners. Res Dev Disabil. 2013; 34(1):695-709.

38. Pan C-Y. The efficacy of an aquatic program on physical fitness and aquatic skills in children with and without autism spectrum disorders. RASD. 2011; 5(1):657-665.

39. Reynolds JL, Pitchford EA, Hauck JL, Ketcheson LR, Ulrich DA. Outcomes of home-support consultation on the maintenance of bicycle-riding skills for youth with autism spectrum disorder. J Educ Psychol Consult. 2015; 26:166-185.

40. Clark J. Motor development, In: Encyclopedia of human behavior. Vol. 3. San Diego: Academic Press; 1994. p 245-255

41. Fragala-Pinkham M, Haley SM, O’Neil ME. Group aquatic aerobic exercise for children with disabilities. DMCN. 2008; 50(11):822-827.

42. Thelen E. Dynamic Systems Theory and the Complexity of Change. Psychoanalytic Dialogues. 2005; 15:255-283.

43. Newell K. Constraints on the development of coordination. Motor Development in Children : Aspects of Coordination and Control. 1986

44. Stodden DF, Goodway JD, Langendorfer SJ, Roberton MA, Rudisill ME, Garcia C, et al. A developmental perspective on the role of motor skill competence in physical activity: An emergent relationship. Quest. 2008; 60(2):290-306.

45. Renshaw I, Chow JY, Davids K, Hammond J. A constraintsled perspective to understanding skill acquisition and game play: a basis for integration of motor learning theory and physical education praxis? Phys Educ Sport 
Pedagogy. 2010; 15(2):117-137.

46. Newell KM. Physical constraints to development of motor skills. Motor development during childhood and adolescence / edited by Jerry R Thomas. 1984

47. Carson V, Lee E-Y, Hewitt L, Jennings C, Hunter S, Kuzik $\mathrm{N}$, et al. Systematic review of the relationships between physical activity and health indicators in the early years (0-4 years). BMC Public Health. 2017; 17(S5):854.

48. Fisher A, Reilly JJ, Kelly LA, Montgomery C, Williamson A, Paton JY, et al. Fundamental movement skills and habitual physical activity in young children. Med Sci Sports Exerc. 2005; 37(4):684-688.

49. Williams HG, Pfeiffer KA, O’Neill JR, Dowda M, McIver

KL, Brown WH, et al. Motor skill performance and physical activity in preschool children. Obesity. 2008;16(6):1421-1426.

50. Sääkslahti A, Numminen P, Niinikoski H, Rask-Nissilä L, Viikari J, Tuominen J, et al. Is physical activity related to body size, fundamental motor skills, and CHD risk factors in early childhood? Pediatr Exerc Sci. 1999; 11(4):327-340.

51. Lin L-Y, Cherng R-J, Chen Y-J. Relationship between time use in physical activity and gross motor performance of preschool children. Aust Occup Ther J. 2017; 64(1):4957.

52. Ku B, MacDonald M, Hatfield B, Gunter KB. Parental influences on parent-reported motor skills in young children with developmental disabilities. Disabil Health J. 2020; 100910.

53. Goodway JD, Branta CF. Influence of a motor skill intervention on fundamental motor skill development of disadvantaged preschool children. Res Q Exer Sport. 2003; 74(1):36-46.

54. Robinson LE, Goodway JD. Instructional climates in preschool children who are at-risk. Part I: object-control skill development. Res Q Exer Sport. 2009; 80(3):533542.

55. Valentini NC, Rudisill ME. An inclusive mastery climate intervention and the motor skill development of children with and without disabilities. APAQ. 2004; 21(4):330-347.

56. Bishop JC, Pangelinan M. Motor skills intervention research of children with disabilities. Res Dev Disabil. 2018; 74:14-30. 